\title{
Growth, Gas Exchange, Water Uptake, and Drought Response of Seedling- and Cutting- propagated Peach and Citrus Rootstocks
}

\author{
Mark Rieger \\ Department of Horticulture, University of Georgia, Athens, GA 30602
}

Additional index words. Prunus persica, Citrus aurantium, Poncirus trifoliata x Citrus sinensis, Lovell, Nemaguard, sour orange, Carrizo citrange, root hydraulic conductivity, root resistance, photosynthesis, leaf conductance

\begin{abstract}
Growth, gas exchange, root hydraulic conductivity, and drought response of seedling and rooted cuttings of Lovell and Nemaguard peach [Prunus persica (L.) Batsch], and Carrizo (Poncirus trifoliata $x$ Citrus sinensis) and sour orange $(C$. aurantium $\mathrm{L}$.) citrus rootstocks were compared to determine the influence of propagation method on these characteristics. Rooted peach cuttings had a higher proportion of root biomass in fibrous roots $(\leq 1 \mathrm{~mm}$ in diameter) and lower root : shoot ratios than seedlings, although this did not occur in citrus. $\mathrm{Net}^{\mathrm{CO}_{2}}$ assimilation (A) was higher for peach seedlings than for cuttings, but similar for 'Redhaven' (RH) scions on either seedling- or cuttingpropagated rootstocks, suggesting that leaf-associated factors were responsible for differences. As in peach, A was higher for Carrizo seedlings than for cuttings, but A was not affected by propagation method in sour orange. Peach seedlings maintained higher A than cuttings as water potentials declined during short-term soil drying, although in citrus this occurred only for Carrizo. RH scions on either root type exhibited similar declines in A as soil dried, indicating the lack of a rootstock effect. Root hydraulic conductivity $\left(\mathrm{L}_{\mathrm{p}}\right)$ was similar between seedlings and cuttings of all cultivars when expressed on a length basis. Leaf conductance and osmotic adjustment were similar for RH scions on seedling- or cutting-propogated rootstocks during 45 days of drought stress, indicating the lack of a rootstock effect on long-term stress response.
\end{abstract}

Development of new clonal rootstocks or own-rooted scions for peach and other Prunus species is a worldwide concern due to the vast number of soil-related factors limiting orchard productivity, and the need to reduce variation among trees (Rom, 1982, 1983). Currently, there is only minor use of clonal rootstocks for peach, although own-rooted scions have achieved limited commercial success (Couvillon, 1985). Studies examining the behavior of peach scions on several rootstocks vs. own-rooted scions are just beginning to appear in the literature. Survival on short-life sites (Reighard et al., 1990), variation among cultivars in yield efficiency (Hammerschlag and Scorza, 1991), and drought stress response (Couvillon et al., 1989) differed between own-rooted and grafted peach trees. However, flower bud hardiness (Durner, 1990) and winter injury (Ferree and Schmid, 1988) were similar for trees on their own roots and those grafted to common peach rootstocks. Reduced tree size of own-rooted scions vs. grafted trees seems to be consistent across location in peach (Couvillon et al., 1989; Frecon, 1986; Marini, 1985), and this effect has been reported for 'Bartlett' pear (Pyrus communis L.) as well (Westwood et al., 1976).

Mechanisms that reduce drought stress in peach trees are worthy of investigation, because supplies of irrigation water are becoming limited, and fruit size and yield are directly related to water availability during the final phase of fruit growth (Chalmers and Wilson, 1978). The objectives were to determine if rooted cutting and seedling peach trees differ with respect to root growth, carbon partitioning, canopy gas exchange, root water uptake, and response to drying soil, all factors that may explain differential growth and drought response. Citrus was compared to peach to determine if effects of propagation method were species specific or similar in widely different taxa. Citrus

Received for publication 15 Jan. 1992. Accepted for publication 27 Apr. 1992. A contribution of the Georgia Agricultural Experiment Stations, College Station, Athens. I thank Michael Duemmel for technical assistance. The cost of publishing this paper was defrayed in part by the payment of page charges. Under postal regulations, this paper therefore must be hereby marked advertisement solely to indicate this fact. rootstocks were ideally suited to this study because seedlings are nucellar and therefore genetically identical to rooted cuttings, whereas in peach, cuttings and seedlings differ genetitally. This comparison permitted determination of the propagation effect exclusive of genetic variability.

\section{Materials and Methods}

Plant material. Terminal semihardwood cuttings and seed of Nemaguard and Lovell peach were collected from the same trees growing on the Horticultural Research Farm in Athens, Ga., in Sept. 1989. Cuttings were rooted as described by Couvillon and Erez (1980) and were 10 to $20 \mathrm{~cm}$ long with dry weights of 1 to $2 \mathrm{~g}$ after rooting. Seeds were stratified at $4 \mathrm{C}$ in moist vermiculite for 3 months and planted in speedling trays in commercial soilless medium (50\% peat, $15 \%$ vermiculite, $35 \%$ perlite) in early Jan. 1990. Seedlings were transplanted to 0.9-liter pots of pure sand on 29 Jan. 1990. Rooted cuttings were placed at $\approx 7 \mathrm{C}$ until 25 Jan. 1990 and then transplanted to 0.9-liter pots with sand medium as well. Trees were grown in a greenhouse with $\approx 70 \%$ light transmission, and day/night cycles of 20-30/ 15-25C. Ten cuttings and 10 seedlings of each cultivar were selected for uniform growth and used for all measurements.

RH peach was budded onto seedling- and cutting-propagated rootstocks of Nemaguard and Lovell on 9 June 1990 to test the influence of rootstock propagation on gas exchange, water relations, and drought response of a common scion. Chip buds were inserted $\approx 10 \mathrm{~cm}$ above the soil line on 9 June and wrapped with parafilm for 2 weeks. Buds were forced on 23 June, and scions had grown 5 to $20 \mathrm{~cm}$ before being placed at $4 \mathrm{C}$ on 9 July for 13 weeks. Trees were removed from the cooler in October and grown under greenhouse conditions as described until measurements were made in Jan.-Feb. 1991. Only Lovell rootstocks produced a sufficient number of trees suitable for labo-

Abbreviations: A, net $\mathrm{CO}_{2}$ assimilation; g, stomatal conductance; $\mathrm{L}_{\mathrm{p}}$, root hydraulic conductivity; NUE, nitrogen-use efficiency; RH, 'Redhaven'; WUE, water-use efficiency; $\Psi$, water potential. 
ratory analyses similar to nongrafted trees; the RH/Nemaguard trees were used only during the longer-term drought response studies described later. Six RH/Lovell seedlings and four RH/ Lovell cuttings were used for measurements of the same variables as the nongrafted trees. The fewer replications of grafted than of nongrafted trees resulted from lack of bud success, nonuniform growth, and failure to induce a lateral shoot on the rootstock shank, which is necessary for drought response and $\mathrm{L}_{\mathrm{p}}$ measurements described later (Rieger and Motisi, 1990).

Carrizo citrange and sour orange were used for comparison to peach trees, because both are highly nucellar and commonly used citrus rootstocks. Seed were obtained from a nursery in Florida, and terminal cuttings, $\approx 20 \mathrm{~cm}$ in length (six to 10 nodes), were taken from 1.5-year-old seedlings in Sept. 1989. Leaves were removed from the basal portion of the cuttings, and stems were wounded and dipped in a solution of $2500 \mu \mathrm{g}$ indole butyric acid/g water. Cuttings were placed in vermiculite flats in a mist bed for 2 months, acclimated to greenhouse conditions for 2 months, then transplanted to 0.9-liter pots of sand on 15 Jan. 1990. Seed of both species were sown in speedling trays of a soilless medium on 19 Dec. 1989, and seedlings were transplanted to 0.9-liter pots of sand on 15 Jan. 1990. For Carrizo, seven replications were used, and six replications were used for sour orange. Again, less replication of citrus than peach was due to lack of uniform growth and lateral shoot induction.

All trees were fertilized with half-strength nutrient solution (Jones, 1985) for the first 4 weeks, then full-strength solution twice weekly, alternating with tap water, until measurements were made June-Aug. 1990. Gas exchange and root hydraulic conductivity (described below) were measured by replication within cultivar, i.e., seedlings and cuttings were measured alternatively until all replicates of a particular cultivar were exhausted. Because 2 to 3 weeks elapsed between measurements among cultivars, statistical comparisons were limited to those between propagation method within cultivar. The design was a factorial combination of five taxa $\times$ two propagation methods. Data were tested by analysis of variance using PROC GLM (SAS, Cary, N.C.).

Gus exchange measurements. Measurements of A, transpiration $(\mathrm{E})$, and stomatal conductance to water vapor $(\mathrm{g})$ were taken on enclosed plant canopies in a semiclosed gas-exchange chamber (Rieger and Motisi, 1990). A vapor pressure gradient (VPG) of $\approx 2.0 \mathrm{kPa}$ was maintained for all measurements; leaves were maintained at 26 to $29 \mathrm{C}$, and three $400-\mathrm{W}$ metal halide lamps were arranged in a $120^{\circ}$ arc to provide saturating irradiance to all areas of the canopy. Irradiance varied from $\approx 2500$ $\mu \mathrm{mol} \cdot \mathrm{m}^{-2} \cdot \mathrm{s}^{-1}$ at the top of the chamber to $\approx 1500 \mu \mathrm{mol} \cdot \mathrm{m}^{-2} \cdot \mathrm{s}^{-1}$ at the bottom. These conditions produced maximal $\mathrm{A}$ and $\mathrm{E}$ for all trees in the study.

$L_{P}$. This was estimated on intact trees as described by Rieger and Motisi (1990). Three E rates were induced on each plant through changing VPG and light intensity. After steady-state E was observed for at least $30 \mathrm{~min}$, the water potential gradient $(\Delta \Psi)$ across the roots was estimated by measuring xylem pressure potential (pressure chamber method) of leaves enclosed in parafilm and aluminum foil at the base of the stems outside the chamber. The rooting medium was saturated $(\Psi \approx 0)$ throughout the measurement period and had a hydraulic conductivity several orders of magnitude higher than that of the roots. Water potential was regressed on water uptake on a fibrous root length or weight basis to estimate $\mathrm{L}_{\mathrm{p}}\left(\right.$ slope $\left.^{-1}\right)$ and the offset (y-intercept).

Response to soil drying. Following estimation of $\mathrm{L}$, the soil was allowed to dry for 4 to 7 days, during which time canopy gas exchange and stem water potential were measured to develop a relationship between $\mathrm{A}$ and $\Psi$ for each type of plant. Saturating irradiance, a temperature of 26 to 29C, and a VPG $\approx 2.0 \mathrm{kPa}$ were maintained for each measurement. Linear and nonlinear regressions of $\mathrm{A}$ on $\Psi$ were calculated from all points for a given cultivar/propagation method subgroup.

Growth measurements. After $\mathrm{L}_{\mathrm{p}}$ and gas exchange measurements were made, trees were divided into leaves, stems, large roots ( $>1 \mathrm{~mm}$ for peach, $>2 \mathrm{~mm}$ for citrus), and fibrous roots. Length of fibrous roots was estimated by the line-intercept method of Tennant (1975) using a $3 \times 3-\mathrm{cm}$ grid. Total root length was estimated first by counting all intercepts, then only suberized roots were counted on a second scan to estimate the fraction of the total root length that was suberized. Leaf area was measured using a LI-3000 area meter (LI-COR, Lincoln, Neb.). Plant materials were dried at $80 \mathrm{C}$ for 1 to 2 weeks to obtain dry weights. Leaf nitrogen content was estimated by Kjeldahl digestion and autoanalyzer (Technicon) on dried leaf tissue. Nitrogen use efficiency (NUE) was calculated as $\mathrm{A} / \mathrm{N}$, where $\mathrm{N}$ is nitrogen content in millimoles per square meter, giving units of mole $\mathrm{C} /$ mole $\mathrm{N}$ per second.

Long-term drought stress. Drought stress was imposed on a separate group of RH scions on either seedling- or cutting-propagated Nemaguard and Lovell rootstocks obtained from the same population as those used for measurements described above. Three trees of each cultivar/propagation method subgroup were watered daily to container capacity, while the other three were given 100 to $150 \mathrm{ml}$ of water every other day to provide a fluctuating water deficit (total $=24$ trees). This volume of water allowed trees in the drought stress treatment to wilt between irrigations but did not cause leaf shedding. Trees were maintained under these conditions for 45 days during Jan.-Mar. 1991. Greenhouse conditions were as described above. Leaf conductance was measured using a steady-state porometer (LICOR) at 9:00, 12:00, and 15:00 HR (Eastern Standard Time) on several days during this period to assess the impact of drought stress on stomatal opening. In addition, leaf osmotic potential at full turgor $\left(\pi_{\mathrm{o}}\right)$ was measured with a thermocouple psychrometer (Decagon Devices, Pullman, Wash.) at the end of the 45-day stress period to determine if osmotic adjustment occurred. Three leaves were collected from each tree in the morning and placed at $4 \mathrm{C}$ with cut ends of petioles immersed in distilled, deionized water. I assumed from previous experience that the water potential of the leaves reached $\approx 0$ after overnight equilibration. Leaves were then held frozen at $-80 \mathrm{C}$ until $\pi_{\mathrm{o}}$ was determined at a later date. Cell sap osmotic potentials were therefore overestimated, because membrane disruption causes dilution of cell sap with relatively pure apoplastic water. No attempt was made to correct for this dilution, as I assumed that the dilution was similar for all leaves.

Leaf conductance and osmotic potential data from long-term stress studies were analyzed separately using analysis of variance for a $2 \times 2 \times 2$ factorial combination of cultivar, propagation method, and irrigation regime, with three single-tree replications (Proc GLM, SAS). The design was completely randomized.

\section{Results and Discussion}

Root system growth and dry weight partitioning. Seedling root systems had a higher dry weight than cuttings for Nemaguard, Lovell, and RH/Lovell, but the opposite effect occurred for the citrus rootstocks (Table 1). In peach, seedlings tended 
Table 1. Growth characteristics of seedlings and rooted cuttings of peach and citrus and RH peach scions budded onto Lovell seedling- or cutting-propagated rootstocks.

\begin{tabular}{|c|c|c|c|c|c|c|c|c|}
\hline \multirow{3}{*}{$\begin{array}{l}\text { Cultivar/ } \\
\text { propagation } \\
\text { method }\end{array}$} & \multirow{2}{*}{\multicolumn{3}{|c|}{ Root dry wt }} & \multirow{2}{*}{\multicolumn{2}{|c|}{ Root length }} & \multicolumn{3}{|c|}{ Whole plant } \\
\hline & & & & & & \multirow{2}{*}{$\begin{array}{c}\text { Root length : } \\
\text { leaf area } \\
\text { ratio }\end{array}$} & \multirow[b]{2}{*}{$\begin{array}{l}\text { Root : shoot } \\
\text { ratio }\end{array}$} & \multirow{2}{*}{$\begin{array}{l}\text { Total plant } \\
\text { dry wt } \\
\text { (g) }\end{array}$} \\
\hline & $\begin{array}{c}\text { Total } \\
(\mathrm{g})\end{array}$ & $\begin{array}{l}\text { Fibrous } \\
(\mathrm{g})\end{array}$ & $\begin{array}{l}\text { Fibrous : } \\
\text { total ratio }\end{array}$ & $\begin{array}{l}\text { Total } \\
(\mathrm{m})\end{array}$ & $\begin{array}{l}\text { Suberized : } \\
\text { total ratio }\end{array}$ & & & \\
\hline \multicolumn{9}{|l|}{ Nemaguard } \\
\hline Cutting & 6.2 & 3.1 & 0.49 & 107 & 0.13 & 1367 & 0.46 & 19.8 \\
\hline \multirow[t]{2}{*}{ Seedling } & 7.8 & 2.8 & 0.38 & 107 & 0.16 & 1551 & 0.67 & 19.2 \\
\hline & $*$ & NS & $* * *$ & NS & NS & $*$ & $* * *$ & NS \\
\hline \multicolumn{9}{|l|}{ Lovell } \\
\hline Cutting & 11.2 & 5.3 & 0.48 & 180 & 0.24 & 2076 & 0.60 & 29.9 \\
\hline \multirow[t]{2}{*}{ Seedling } & 15.5 & 4.8 & 0.31 & 182 & 0.21 & 2703 & 1.17 & 28.7 \\
\hline & $* * *$ & NS & $* * *$ & NS & NS & $*$ & $* * *$ & NS \\
\hline \multicolumn{9}{|l|}{ RH/Lovell } \\
\hline Cutting & 8.1 & 3.7 & 0.46 & 172 & 0.84 & 1926 & 0.74 & 18.9 \\
\hline \multirow[t]{2}{*}{ Seedling } & 14.8 & 5.6 & 0.38 & 224 & 0.84 & 2251 & 1.35 & 25.8 \\
\hline & $* *$ & $*$ & $*$ & $* *$ & NS & NS & $* * *$ & $* * *$ \\
\hline \multicolumn{9}{|l|}{ Carrizo } \\
\hline Cutting & 13.7 & 6.1 & 0.45 & 64 & 0.18 & 1431 & 0.80 & 30.8 \\
\hline \multirow[t]{2}{*}{ Seedling } & 7.0 & 2.8 & 0.41 & 36 & 0.06 & 1536 & 0.63 & 18.1 \\
\hline & $* * *$ & $* * *$ & NS & $* * *$ & $* * *$ & NS & $* * *$ & $* * *$ \\
\hline \multicolumn{9}{|l|}{ Sour orange } \\
\hline Cutting & 14.2 & 6.1 & 0.43 & 55 & 0.23 & 479 & 0.68 & 35.1 \\
\hline \multirow[t]{2}{*}{ Seedling } & 7.3 & 3.1 & 0.43 & 30 & 0.19 & 384 & 0.58 & 19.9 \\
\hline & $* * *$ & $* *$ & NS & $* * *$ & NS & $*$ & $*$ & $* * *$ \\
\hline
\end{tabular}

$\mathrm{NS}, *, * * * * *$ Paired comparison between cuttings and seedlings within a cultivar nonsignificant at $P>0.05$ or significant at $P=0.05,0.01$, and 0.001 , respectively. For Lovell and Nemaguard, $\mathrm{n}=10$; Carrizo, $\mathrm{n}=7$; sour orange, $\mathrm{n}=6$; $\mathrm{RH}$ on seedling or cutting rootstocks, $\mathrm{n}=6$ and $\mathrm{n}=4$, respectively.

to produce relatively large taproots that comprised most of the root system mass, whereas cuttings produced very few largediameter roots. Consequently, peach seedling root systems had a lower proportion of root biomass in fibrous $(\leq 1 \mathrm{~mm})$ roots than in larger, structural roots, although fibrous root weights were similar for seedlings and cuttings. Similarly, RH/Lovell cuttings had less total root weight and a greater proportion of root biomass in fibrous roots than those on seedling rootstocks. Thus, the larger size of the root system and greater proportion of biomass in large roots of seedlings was conserved from initial growth through budding, cold storage, and regrowth. These morphological features are consistent with those observed previously on larger, nursery-grown peach trees (Couvillon et al., 1989), indicating that pot culture did not qualitatively affect root characteristics.

The larger seedling root systems resulted in higher root : shoot ratios for seedlings than cuttings for Nemaguard, Lovell, and RH/Lovell (Table 1). Carrizo and sour orange, in contrast, had higher root : shoot ratios for cuttings than seedlings. A high root : shoot ratio may be beneficial in drought tolerance if all the roots contribute to water uptake equally, indicating better stress tolerance for peach seedlings than cuttings, which is opposite of that previously reported (Couvillon et al., 1989). However, a large portion of seedling root system weights was incorporated into large, woody roots with little surface area, which probably made little contribution to water absorption. A related study on Eucalyptus grandis W. Hill ex Maiden showed that seedlings had a higher root : shoot ratio than cuttings, as found here with peach, and maintained higher daytime $\Psi$ than cuttings (Blake and Filho, 1988). However, the Eucalyptus seedlings also had lower leaf conductance than cuttings, which alone could have been responsible for maintenance of higher $\Psi$. Probably of greater importance is the fibrous root length : leaf area ratio in regulating plant water status. This ratio was higher for seedlings than cuttings of Nemaguard and Lovell, but was similar for RH/Lovell trees, suggesting that this initial difference is lost after trees are grafted and cut back. Thus, any advantaged seedlings may have over cuttings in the nursery may have little bearing on the subsequent performance of grafted trees. Only for sour orange was the root length : leaf area ratio higher for cuttings than seedlings. Such inconsistencies in results among taxa in this study and between the current and previous studies make conclusions regarding relative drought tolerance of cuttings vs. seedlings and root/shoot balance tenuous.

Root length did not differ between nongrafted seedling and cutting peaches but was less for RH/Lovell on cutting than seedling root systems (Table 1). The suberized root percentage was unaffected by propagation method in peach but seemed to increase with plant age, because grafted trees had a much higher suberized root percentage than nongrafted and were also several months older than nongrafted trees. The degree of suberization of roots is known to increase with age in fruit trees and may approach $100 \%$ in winter (Atkinson, 1980). In citrus, roots were longer for cuttings than seedlings, but the degree of suberization was different only for Carrizo, where cuttings had three times the number of suberized roots for seedlings.

In peach, total plant weight differed between seedlings and cuttings only for grafted trees, where seedling rootstocks produced larger trees than cutting rootstocks (Table 1). This difference was due entirely to the larger root system for trees on seedling rootstocks, because stem and leaf weights of RH scions did not differ with rootstock propagation method (data not shown). Lack of differences in shoot weights between RH scions on cutting and seedling rootstocks may have been due to high variability induced by recent budding and removal of rootstock canopies. Thus, reasons for the smaller canopy size of own- 
rooted vs. grafted peach trees remain unclear but may be related to initial differences in root mass.

In citrus, cuttings had higher shoot and root weights than seedlings. This difference may have been due to retention of leaves during and following rooting, resulting in a larger leaf area for a longer duration and consequently greater cumulative carbon gain for cuttings than seedlings over the same growth period. Unlike those of peach, citrus root systems partitioned $\approx 40 \%$ to $45 \%$ of the biomass into fibrous roots, regardless of propagation method and despite large differences in root mass. Conflicting results for peach and citrus indicate that growth response to propagation method may be species dependent.

Gas exchange. Seedlings had A rates $\approx 50 \%$ higher than cuttings for all nongrafted trees, except sour orange (Table 2). For peach, this difference appeared to be caused by leaf-associated factors, because RH scions with either rootstock type had similar gas exchange characteristics when well-watered and as soil dried progressively (Fig. 1c). This relationship suggests that the juvenile leaf type for peach has a greater capacity for A than the mature leaf type (present on rooted cuttings and grafted trees) regardless of cultivar. The basis for the higher A in Carrizo seedlings than cuttings is unclear, because leaves on both types were similar with respect to leaf morphology, nitrogen content, and NUE (Table 2). Alternatively, higher A for peach seedling leaves may have been related to lower specific leaf weight, lower area per blade (not shown), and/or higher NUE than for cuttings. Higher NUE in peach seedlings occurred despite their lower nitrogen content than in cuttings of both cultivars. This result suggests that juvenile leaves have an inherently greater ability to use nitrogen with respect to A than mature leaves. Cregg et al. (1989) also showed that leaves on seedlings have higher $\mathrm{A}$ and different morphology than those on mature trees for several forest species.
Similarity in dry weight for peach cuttings and seedlings at the end of the study was probably due to offsetting effects of lower leaf area, shorter leaf area duration, and higher $\mathrm{A}$ in seedlings vs. cuttings. Leaf area was $13 \%$ and $24 \%$ higher in cuttings than in seedlings of Nemaguard and Lovell, respectively, and seedlings developed foliage at a slower rate than cuttings during the first part of the growth period. For Carrizo, lower $\mathrm{A}$ in cuttings than in seedlings was more than offset by a 92\% larger leaf area in cuttings and longer leaf area duration. Similarly, the $50 \%$ larger leaf area for sour orange cuttings than seedlings allowed greater dry weight accumulation for cuttings despite similar A.

In Nemaguard and Carrizo, g was higher for seedlings than cuttings. Greater $\mathrm{g}$ may explain higher $\mathrm{A}$ for seedlings than cuttings of Nemaguard, because intercellular $\mathrm{CO}_{2}$ concentration (Ci) was higher for seedlings of this cultivar, potentially giving rise to higher $\mathrm{CO}_{2}$ assimilation. However, higher levels of $\mathrm{A}$ for Carrizo seedlings than cuttings cannot be explained by $\mathrm{g}$, because $\mathrm{C}_{\mathrm{i}}$ was similar for seedlings and cuttings. The discrepancy in $\mathrm{A}$ for Lovell also cannot be explained by differences in $\mathrm{C}_{\mathrm{i}}$. Evidently, nonstomatal factors were responsible for reduced A in Lovell and Carrizo cuttings compared to seedlings.

For all cultivars, A increased asymptotically with $\mathrm{g}$, so that further increases in $\mathrm{g}$ above $200 \mathrm{mmol} \cdot \mathrm{m}^{-2} \cdot \mathrm{s}^{-1}$ in peach and $150 \mathrm{mmol} \cdot \mathrm{m}^{-2} \cdot \mathrm{s}^{-1}$ in citrus gave rise to increases in $\mathrm{A}$ of $<10 \%$ (data not shown). Increases in $\mathrm{g}$ above these levels might reduce water use efficiency (WUE), because E increases linearly, yet A increases a negligible amount as stomatal aperture widens. This difference may explain lower WUE for Nemaguard seedlings than cuttings, because $\mathrm{g}$ for seedlings was well above the level where A was substantially influenced by g. However, the higher WUE for Lovell seedlings than cuttings cannot be explained as a stomatal effect and could only be due to differences

Table 2. Leaf and gas exchange characteristics of seedlings and rooted cuttings of peach and citrus and RH scions budded onto Lovell rootstocks.

\begin{tabular}{|c|c|c|c|c|c|c|c|}
\hline $\begin{array}{l}\text { Cultivar/ } \\
\text { propagation } \\
\text { method }\end{array}$ & $\begin{array}{c}\text { Leaf } \mathrm{N} \\
\left(\mathrm{mmol} \cdot \mathrm{m}^{-2}\right)\end{array}$ & $\begin{array}{c}\text { NUE } \\
(\mathrm{mol} \mathrm{C} / \mathrm{mol} \mathrm{N} \text { per } \\
\left.\sec \times 10^{3}\right)\end{array}$ & $\begin{array}{c}\mathrm{SLW}^{\mathrm{z}} \\
\left(\mathrm{g} \cdot \mathrm{m}^{-2} \times 10^{3}\right) \\
\end{array}$ & $\begin{array}{c}\mathrm{A} \\
\left(\mu \mathrm{mol} \cdot \mathrm{m}^{-2} \cdot \mathrm{s}^{-1}\right)\end{array}$ & $\stackrel{\mathrm{g}}{\left(\mathrm{mmol} \cdot \mathrm{m}^{-2} \cdot \mathrm{s}^{-1}\right)}$ & $\begin{array}{c}\text { WUE } \\
\left(\mathrm{mol} \mathrm{CO}_{2} /\right. \\
\left.\mathrm{mol} \mathrm{H}_{2} \mathrm{O}\right)\end{array}$ & $\begin{array}{c}\mathrm{C}_{\mathrm{i}} \\
\left(\mu \mathrm{l} \cdot \text { liter }^{-1}\right)\end{array}$ \\
\hline \multicolumn{8}{|l|}{ Nemaguard } \\
\hline Cutting & 12.9 & 0.86 & 10.9 & 10.9 & 154 & 0.0063 & 232 \\
\hline \multirow[t]{2}{*}{ Seedling } & 9.7 & 1.57 & 6.5 & 15.0 & 317 & 0.0050 & 265 \\
\hline & $* *$ & $* *$ & $* * *$ & $* * *$ & $* * *$ & $* * *$ & $* *$ \\
\hline \multicolumn{8}{|l|}{ Lovell } \\
\hline Cutting & 11.8 & 0.91 & 11.3 & 10.4 & 196 & 0.0049 & 254 \\
\hline \multirow[t]{2}{*}{ Seedling } & 10.3 & 1.51 & 7.4 & 15.3 & 270 & 0.0056 & 242 \\
\hline & $*$ & $* *$ & $* * *$ & $* *$ & NS & * & NS \\
\hline \multicolumn{8}{|l|}{ RH/Lovell } \\
\hline Cutting & 10.2 & 0.96 & 4.3 & 9.8 & 122 & 0.0044 & 224 \\
\hline \multirow[t]{2}{*}{ Seedling } & 11.6 & 0.91 & 4.4 & 10.7 & 169 & 0.0041 & 238 \\
\hline & NS & NS & NS & NS & NS & NS & NS \\
\hline \multicolumn{8}{|l|}{ Carrizo } \\
\hline Cutting & 7.6 & 1.32 & 8.1 & 10.1 & 138 & 0.0054 & 229 \\
\hline \multirow[t]{2}{*}{ Seedling } & 10.1 & 1.43 & 8.6 & 14.5 & 223 & 0.0057 & 235 \\
\hline & $* *$ & NS & NS & $*$ & $*$ & NS & NS \\
\hline \multicolumn{8}{|l|}{ Sour orange } \\
\hline Cutting & 9.1 & 0.72 & 11.3 & 6.3 & 99 & 0.0050 & 236 \\
\hline \multirow[t]{2}{*}{ Seedling } & 9.2 & 0.68 & 9.2 & 6.4 & 91 & 0.0048 & 240 \\
\hline & NS & NS & NS & NS & NS & NS & NS \\
\hline
\end{tabular}

NS*,*****Paired comparison between cuttings and seedlings within a cultivar nonsignificant at $P>0.05$ or significant at $P=0.05,0.01$, and 0.001 , respectively. For Lovell and Nemaguard, $\mathrm{n}=10$; Carrizo, $\mathrm{n}=7$; sour orange, $\mathrm{n}=6$; $\mathrm{RH}$ on seedling and cutting rootstocks, $\mathrm{n}=6$ and $\mathrm{n}=4$, respectively.

${ }^{\mathrm{z}} \mathrm{SLW}=$ specific leaf weight. 

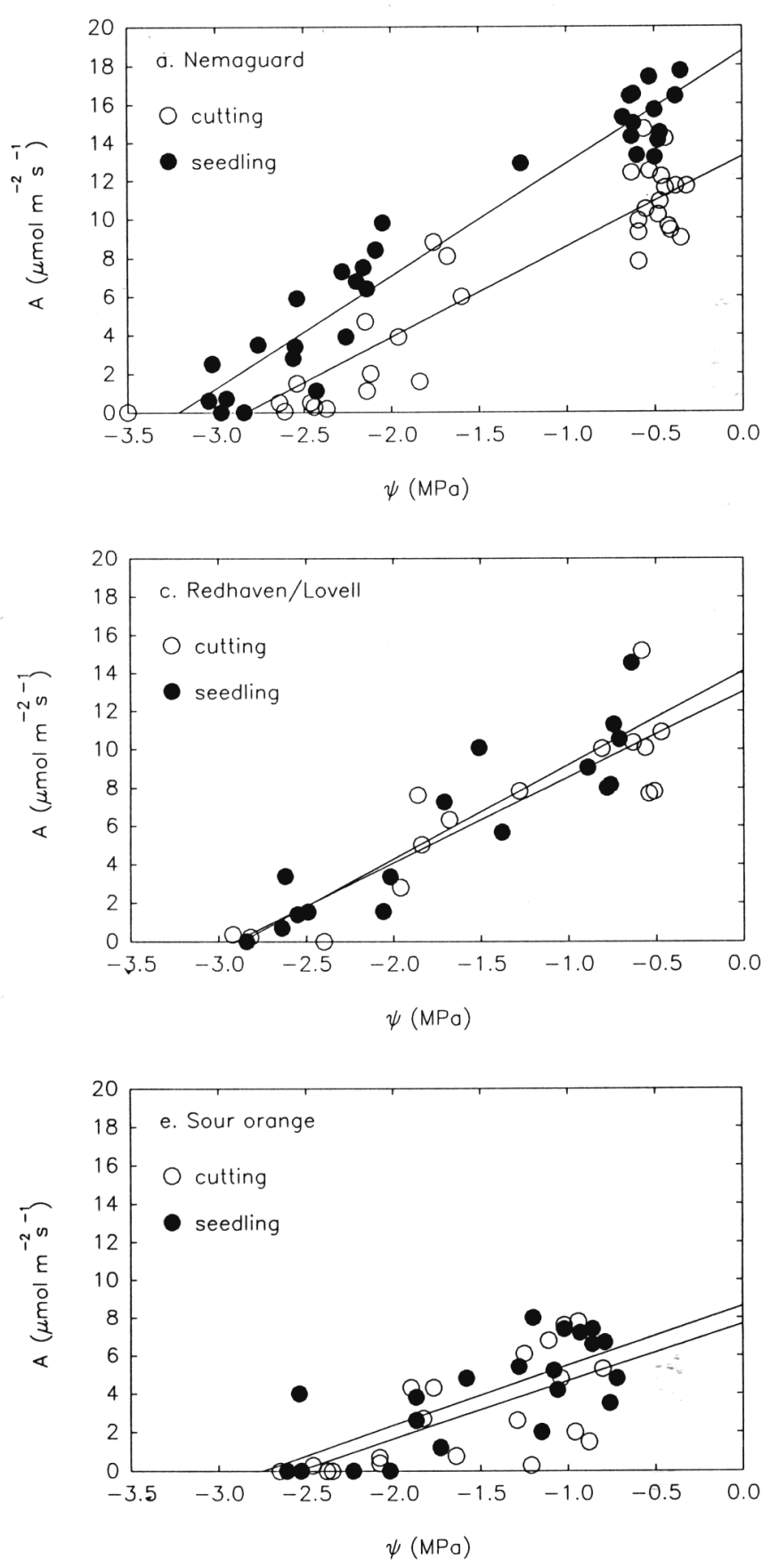

in assimilation capacity, because measurements were made at the same VPG. Despite inconsistent differences in WUE in nongrafted peach trees, propagation method clearly does not influence WUE of a common scion, because genetically indentical leaves on seedlings and cuttings of RH/Lovell, Carrizo, and sour orange had similar WUE.

Differences between seedlings and cuttings in canopy gas exchange appear to be attributable to differences in leaf physiology, not root characteristics. This contention is' supported by the lack of differences in gas exchange between RH scions grafted on seedling and cutting rootstocks. Further, differences in gas exchange between seedling- and cutting-propagated peach trees were corroborated by Carrizo only, suggesting that these differences are not a general result of propagation method and may be unpredictable among species and cultivar specific within species.
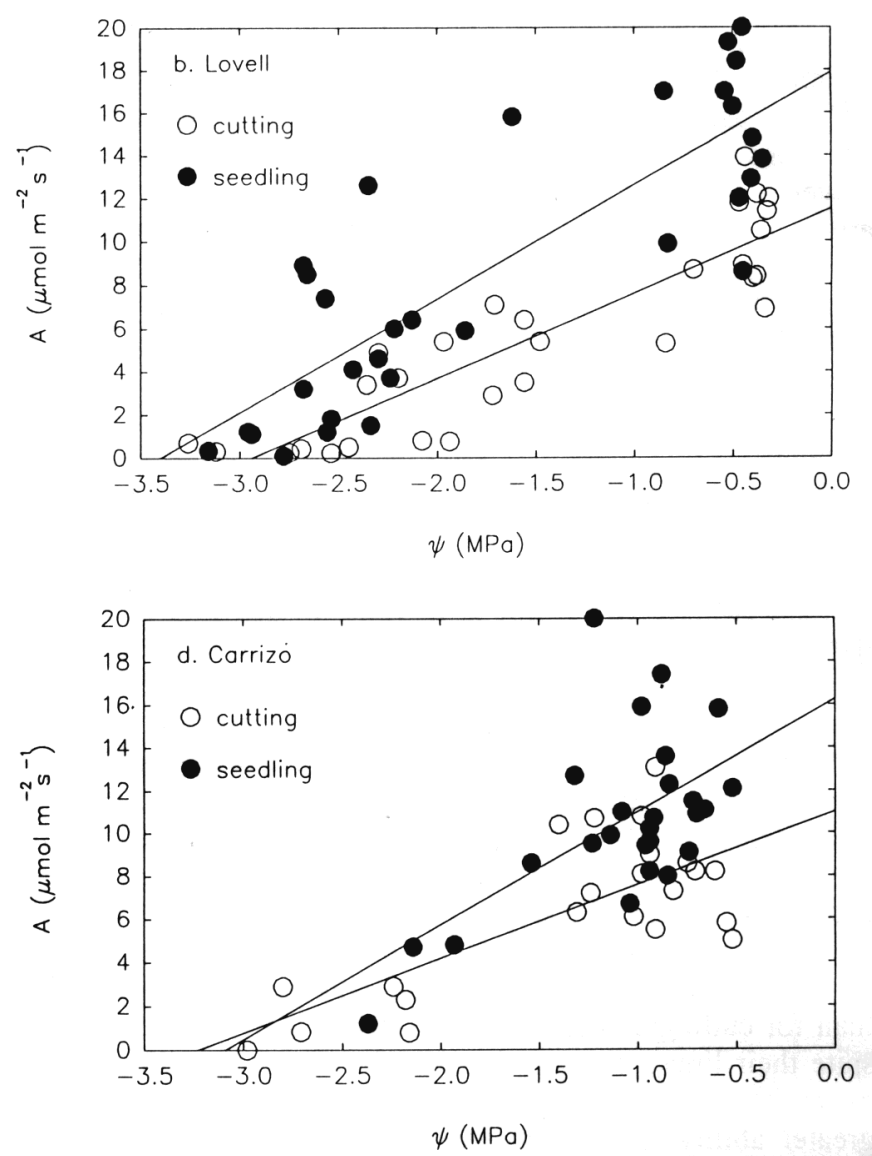

Fig. 1. A vs. $\Psi$ during 4 to 7 days of soil drying for seedling and cutting-propagated Nemaguard peach (a), Lovell peach (b), RH scions on seedling- and cutting-propagated Lovell rootstocks (c), Carrizo citrange (d), and sour orange (e). Regression equations were as follows: (a) cutting: $\mathrm{A}=3.9(\Psi)+11.5, r^{2}=0.80$; seedling: $\mathrm{A}$ $=5.3(\Psi)+17.8, r^{2}=0.70$; (b) cutting: $\mathrm{A}=4.7(\Psi)+13.2$, $r^{2}=0.84$; seedling: $\mathrm{A}=5.8(\Psi)+18.7, r^{2}=0.93$; (c) $\mathrm{RH} /$ cutting: $\mathrm{A}=4.5(\Psi)+13.0, r^{2}=0.79 ; \mathrm{RH} /$ seedling: $\mathrm{A}=4.9(\Psi)$ $+14.1, r^{2}=0.82$; (d) cutting: $\mathrm{A}=3.4(\Psi)+11.0, r^{2}=0.54$; seedling: $\mathrm{A}=5.3(\Psi)+16.3, r^{2}=0.35$; (e) cutting: $\mathrm{A}=3.0(\Psi)$ $+7.7, r^{2}=0.44$; seedling: $\mathrm{A}=3.1(\Psi)+8.6, r^{2}=0.55$. For nongrafted Nemaguard (a) and Lovell (b), slopes were significantly greater, x-intercepts were lower, and y-intercepts higher for seedlings than for cuttings $(P<0.05)$. For Carrizo $(\mathbf{d})$, slope was significantly greater and $\mathrm{x}$ - and $\mathrm{y}$-intercepts higher for seedlings than for cuttings. Slope and intercepts were not different for seedlings vs. cuttings in $\mathrm{RH} /$ Lovell (c) and sour orange (e).

Response to soil drying. Net $\mathrm{CO}_{2}$ assimilation decreased linearly with $\Psi$ during short-term soil drying for all trees studied (Fig. 1a-e). Similar linear responses of A to $\Psi$ have been reported for peach seedlings (Tan and Buttery, 1982) and other fruit tree species (Germana and Sardo, 1990; Jorba et al., 1984; Lankes, 1984) when short-term soil drying is imposed. Seedlings of Nemaguard, Lovell, and Carrizo maintained higher A as $\Psi$ declined, with peach seedlings maintaining positive A to lower $\Psi$ than cutting and vice-versa for Carrizo. Data were normalized by dividing all $\mathrm{A}$ values into the maximal $\mathrm{A}$ value obtained for a given treatment, yielding the sensitivity of $\mathrm{A}$ to $\Psi$ (percent decrease in A per MPa decrease in $\Psi$ ). Sensitivity was similar for seedlings and cuttings of both citrus cultivars, but variable in peach; seedlings were less sensitive than cuttings for Lovell, but more sensitive than cuttings for Nemaguard. Thus, the sensitivity of A to declining soil moisture appears to 
be cultivar specific and not consistently affected by propagation method. With the exception of Carrizo, it does not appear that the response of A to $\Psi$ is controlled by root-based factors, because the response of a common scion (RH/Lovell, sour orange) was similar.

$L_{p}$. In all cases, $L_{p}$ was similar between seedling and cutting root systems when expressed on a root-length basis (Table 3 ). When expressed on a root-weight basis, differences in $\mathrm{L}_{\mathrm{p}}$ occurred only in RH/Lovell and Carrizo. Thus, the intrinsic ability of a given length of fibrous root to absorb water did not differ between adventitious and true root types, and differential drought tolerance cannot be explained by $\mathrm{L}_{\mathrm{p}}$. Lower $\mathrm{L}_{\mathrm{p}}$ on a weight basis for RH/Lovell seedling peaches probably reflects the reduced water absorption abilities of their larger, woody roots, which comprised most of the root system weight. This difference may be important when considering plant efficiency in terms of water absorption ability per unit carbon investment in roots, but most likely does not explain differential drought tolerance. On a weight basis, higher $\mathrm{L}_{\mathrm{p}}$ for Carrizo seedlings than for cuttings cannot be explained by differences in root dry weight distribution, however.

The offset represents the residual $\Psi$ in the root xylem that exists at zero flow through roots and can be interpreted as the minimum water potential gradient required to permit flow across roots (Passioura and Munns, 1984; Rieger and Motisi, 1990). This characteristic was similar for seedlings and cuttings of all cultivars. However, peach cultivars had offsets of lower magnitude than citrus, which was found previously (Rieger and Motisi, 1990). Also, the offsets for Lovell rootstocks increased following the budding, cold storage, and regrowth period, indicating a possible effect of aging and/or low temperature on this variable, but not $\mathrm{L}$,. The significance of the offset is that trees with similar $\mathrm{L}_{\mathrm{p}}$ must still develop more negative shoot

Table 3. $\mathrm{L}_{\mathrm{p}}$ and minimum gradient required for flow (offset) in seedlings and rooted cuttings of peach and citrus and RH scions budded onto Lovell rootstocks.

\begin{tabular}{lccc}
\hline \hline $\begin{array}{l}\text { Cultivar/ } \\
\text { propagation } \\
\text { method }\end{array}$ & $\begin{array}{c}\text { Length basis } \\
\left(\mathrm{g} \cdot \mathrm{m}^{-1} \cdot \mathrm{MPa}^{-1} \mathrm{per} \mathrm{h}\right)\end{array}$ & $\begin{array}{c}\text { Wt basis } \\
\left(\mathrm{g} \cdot \mathrm{g}^{-1} \cdot \mathrm{MPa}^{-1} \mathrm{per} \mathrm{h}\right)\end{array}$ & $\begin{array}{c}\text { Offset } \\
(\mathrm{MPa})\end{array}$ \\
\cline { 2 - 3 } Nemaguard & & & \\
$\quad$ Cutting & 0.36 & 6.05 & -0.31 \\
Seedling & 0.43 & 6.38 & -0.30 \\
& $\mathrm{NS}$ & $\mathrm{NS}$ & $\mathrm{NS}$ \\
Lovell & & & \\
Cutting & 0.37 & 6.08 & -0.26 \\
Seedling & 0.36 & 4.39 & -0.31 \\
& $\mathrm{NS}$ & $\mathrm{NS}$ & $\mathrm{NS}$ \\
RH/Lovell & & & \\
Cutting & 0.33 & 6.94 & -0.37 \\
Seedling & 0.24 & 3.42 & -0.45 \\
& $\mathrm{NS}$ & $* *$ & $\mathrm{NS}$ \\
Carrizo & & & \\
Cutting & 0.21 & 0.98 & -0.55 \\
Seedling & 0.25 & 1.31 & -0.44 \\
& $\mathrm{NS}$ & $*$ & $\mathrm{NS}$ \\
Sour orange & & & \\
Cutting & 0.32 & 1.24 & -0.59 \\
Seedling & 0.40 & 1.60 & -0.50 \\
& $\mathrm{NS}$ & $\mathrm{NS}$ & $\mathrm{NS}$ \\
\hline
\end{tabular}

NS, $* * * * * *$ Comparison between cutting and seedling within a cultivar nonsignificant at $P>0.05$ or significant at $P=0.05,0.01$, and 0.001 , respectively. water potentials to sustain the same $\mathrm{E}$ if the offset is large (more negative) than if small (close to zero). In any event, neither the offset nor $\mathrm{L}_{\mathrm{p}}$ can explain the differential drought response between seedlings and cuttings reported previously (Couvillon et al., 1989).

Suberization has been shown to reduce water-absorbing ability of roots (Drew 1979; Sands et al., 1982), yet was not significantly related to $L_{p}$ in peach in this study (Fig. 2). This result supports speculation that suberization may not materially affect the ability of fruit tree roots to absorb water (Atkinson, 1980). However, the magnitude of the offset was correlated with the extent of root suberization, and a causal relationship may exist between these characteristics.

Long-term drought stress. Drought stress significantly reduced $\mathrm{g}$ at 4, 20, and 40 days after stress had been imposed compared to well-watered trees, but no differences in $\mathrm{g}$ were detected among RH scions on seedling and cutting rootstocks for either Lovell or Nemaguard. Well-watered trees typically had $\mathrm{g}$ of 100 to $300 \mathrm{mmol} \cdot \mathrm{m}^{-2} \cdot \mathrm{s}^{-1}$, whereas drought-stressed trees had $\mathrm{g}$ of 25 to $75 \mathrm{mmol} \cdot \mathrm{m}^{-2} \cdot \mathrm{s}^{-1}$ during the warmest, driest period of the day. Rootstock propagation method and cultivar appeared to have little influence on $\mathrm{g}$ of a common scion when well-watered or during moderate drought stress. This finding conflicts with previous observations of higher $\mathrm{g}$ and $\Psi$ in ownrooted Lovell trees vs. RH grafted to Lovell seedling rootstock when water was withheld (Couvillon et al., 1989), although the comparison is not exactly the same. The presence of a graft union in trees in this but not the former study was unlikely responsible for conflicting results, as compatible graft unions present no impedance to water flow (Gur and Blum, 1975). Alternatively, the conflicting results may indicate that differences in growth conditions influence the relative behavior of cutting- and seedling-propagated peach trees.

Long-term drought stress reduced leaf $\pi_{\mathrm{o}}$ by $\approx 0.5 \mathrm{MPa}$ for $\mathrm{RH}$ scions regardless of rootstock propagation method or cultivar. All interactions between rootstock cultivar, propagation method, and irrigation regime were nonsignificant, yet the main effects of these variables were all significant $(\mathrm{P} \leq 0.05)$. Specifically, Nemaguard reduced $\pi_{\mathrm{o}}$ by $0.28 \mathrm{MPa}$ compared to Lovell, and trees on cutting rootstocks had $\pi_{\mathrm{o}} 0.2 \mathrm{MPa}$ less than trees on seedling rootstocks. However, despite overall differences in $\pi_{\mathrm{o}}$ due to propagation method, osmotic adjustment

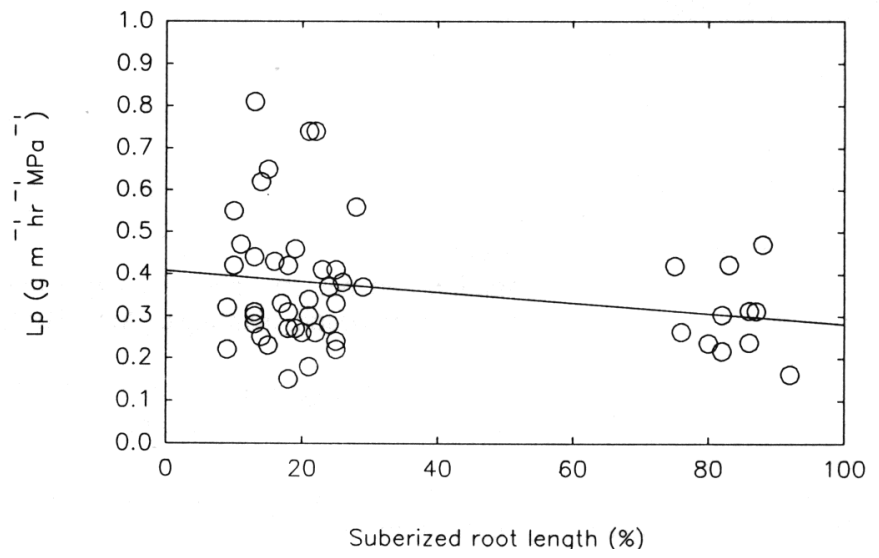

Fig. 2. $\mathrm{L}_{\mathrm{p}}$ vs. the percentage of suberized roots $(\leq 1 \mathrm{~mm}$ in diameter) for rooted cuttings and seedlings of Lovell and Nemaguard peach (points on left) and cutting- and seedling-propagated Lovell rootstocks budded with RH scions (points on right). Regression equation: $L_{p}=-0.00126$ (suberized root length percentage) $+0.41, r^{2}$ $=0.05$. Slope not significantly different from zero, $P=0.05$. 
occurred to the same degree in response to drought stress for trees on seedling and cutting rootstocks of both cultivars. Propagation method apparently does not influence the ability of a common scion to adapt to drought and maintain turgor during prolonged drought stress.

Many of the differences between cuttings and seedlings for variables measured in this study seemed to be either species or cultivar specific rather than a general result of propagation method. In apple (Malus domestica Borkh.), differences in growth and fruiting among own-rooted trees and those on various rootstocks were highly cultivar dependent as well (Larsen and Higgins, 1990; Webster et al., 1985). Within peach or citrus, however, similar trends were observed in root morphology, dry weight partitioning, and total plant weight accumulation between cultivars. These trends support growth observations made previously but do not provide a clear explanation for differences in drought tolerance noted by Couvillon et al. (1989). The smaller size of own-rooted peach trees and more branched, fibrous root systems may contribute to dehydration postponement in the field and partially explain their better performance during drought stress than that of trees grafted on seedling rootstocks.

Overall, peach seedlings appear to be superior to rooted cuttings with respect to nursery characteristics, because they are easier to propagate and partition more mass into roots, which is the only portion of the tree conserved after grafting. Further, seedlings maintained higher A during drought stress, which may confer a competitive advantage over rooted cuttings in nurseries where irrigation water is limited or drought stress is common.

Physiologically, differences in gas exchange between peach cuttings and seedlings were caused by differences in leaf rather than root characteristics. This result suggests that extrapolation of gas exchange or drought response data obtained with peach seedlings to mature trees may be inappropriate given that stomatal and nonstomatal factors vary between the two. Alternatively, use of rooted cuttings for gas exchange studies may provide a more accurate representation of the behavior of leaves on mature, grafted peach trees. Although speculative, it follows that peach productivity might be increased if juvenile leaf characteristics could be maintained in mature, bearing scion cultivars. The specific mechanisms responsible for higher $\mathrm{A}$ in juvenile leaves merit further investigation.

\section{Literature Cited}

Atkinson, D. 1980. The distribution and effectiveness of the roots of tree crops. Hort. Rev. 2:424-490.

Blake, T.J. and W.S. Filho. 1988. Drought tolerance, growth partitioning and vigor in evcalypt seedlings and rooted cuttings. Tree Physiol. 4:325-335.

Chalmers, D.J. and I.B. Wilson. 1978. Productivity of peach trees: Tree growth and water stress in relation to fruit growth and assimilate demand. Ann. Bot. 42:285-294.

Couvillon, G.A. 1985. Propagation and performance of inexpensive trees from cuttings for high density peach plantings. Acta Hort. 173:271-282.

Couvillon, G.A. and A. Erez. 1980. Rooting, survival and development of several peach cultivars propagated from semihardwood cuttings. HortScience 15:41-43.

Couvillon, G.A., M. Rieger, R. Harrison, J. Daniell, and J.G. Aparisi. 1989. Stress-mediated responses of own rooted peach cultivars. Acta Hort. 243:221-230.
Cregg, B.M., J.E. Harpin, P.M. Dougherty, and R.O. Teskey. 1989. Comparative physiology and morphology of seedling and mature forest trees, p. 111-118. In: R.D. Noble, J.L. Martin, and K.F. Jensen (eds.). Air pollution effects on vegetation. U.S. Dept. Agr. For. Serv., Northeastern For. Expt. Sta., Broomall, Pa.

Drew, M.C. 1979. Properties of roots which influence rates of absorption, p. 21-39. In: J.L. Harley and R.S. Russel (eds.). The soil-root interface. Academic, New York.

Durner, E.F. 1990. Rootstock influence on flower bud hardiness and yield of 'Redhaven' peach. HortScience 25:172-173.

Ferree, D.C. and J.C. Schmid. 1988. Performance of selected peach rootstocks in Ohio. Fruit Var. J. 42(3):85-87.

Frecon, J.L. 1986. Self rooted peach trees. Pa. Fruit News 65(4):4951.

Germana, C. and V. Sardo. 1990. Water status and physiological activity in orange trees. XXIIIrd Intl. Hort. Congr., Florence, Italy, Aug. 1990. p. 276. (Abstr.)

Gur, A. and A. Blum. 1975. The water conductivity of defective graft unions in pome and stone fruits. J. Amer. Soc. Hort. Sci. 100:325328.

Hammerschlag, F.A. and R. Scorza. 1991. Field performance of micropropagated, own-rooted peach trees. J. Amer. Soc. Hort. Sci. 116:1089-1091.

Jones, J.B. 1985. Growing plants hydroponically. Amer. Biol. Teacher 47:356-358.

Jorba, J., L. Tapia, and D. Sant. 1984. Photosynthesis, leaf water potential, and conductance in Olea europaea under wet and drought conditions. Acta Hort. 171:237-246.

Lankes, C. 1984. Effect of water stress on transpiration and $\mathrm{CO}_{2}$ gas exchange of the apple leaf and fruit. Acta Hort. 171:305-314.

Larsen, F.E. and S.S. Higgins. 1990. Early performance of self-rooted, micropropagated apple cultivars vs. trees on seedling or M.7a rootstocks. Fruit Var. J. 44(4):185-192.

Marini, R. 1985. Performance of own-rooted peach trees: Preliminary report. Hort. News 65:42-44.

Passioura, J.B. and R. Munns. 1984. Hydraulic resistance in plants II. Effects of rooting medium and time of day in barley and lupin. Austral. J. Plant Physiol. 11:341-350.

Reighard, G.L., W.A. Watson, D.C. Coston, and J.D. Ridley. 1990. Survival of own-rooted and budded 'Redhaven' trees on a peach tree short life site. HortScience 25:359.

Rieger, M. and A. Motisi. 1990. Estimation of root hydraulic conductivity on intact peach and citrus rootstocks. HortScience 25:16311634.

Rom, R.C. 1982. A new philosophy for peach rootstock development. Fruit Var. J. 36(2):34-36.

Rom, R.C. 1983. The peach rootstock situation: An international perspective. Fruit Var. J. 37(1):3-14.

Sands, R., E.L. Fiscus, and C.P.P. Reid. 1982. Hydraulic properties of pine and bean roots with varying degrees of suberization, vascular differentiation and mycorrhizal infection. Austral. J. Plant Physiol. 9:559-569.

Tan, C.S. and B.R. Buttery. 1982. Response of stomatal conductance, transpiration, photosynthesis, and leaf water potential in peach seedlings to different watering regimes. HortScience 17:222-223.

Tennant, D. 1975. A test of a modified line intersect method of estimating root length. J. Ecol. 63:995-1001.

Webster, A.D., V.H. Oehl, J.E. Jackson, and O.P. Jones. 1985. The orchard establishment, growth and precocity of four micropropagated apple scion cultivars. J. Hort. Sci. 60:169-180.

Westwood, M.N., P.B. Lombard, and H.O. Bjornstand. 1976. Performance of 'Bartlett' pear on standard and Old Home x Farmingdale clonal rootstocks. J. Amer. Soc. Hort. Sci. 101:161-164. 